\title{
Reinventando a educação para reinventar a mídia
}

Ismar de Oliveira Soares

Professor titular da ECA/USP, supervisor do curso a distância "Mídias na Educação", do MEC, no Estado de São Paulo, e coordenador da licenciatura em

Educomunicaşão da ECA/USP.

E-mail: ismarolive@yahoo.com

Resumo: $\bigcirc$ artigo faz uma análise de três obras que privilegiam - cada uma sob uma perspectiva distinta - a mídia educação: Educomunicação: imagens do professor na mídia, coordenado por Adilson Citelli; Reinventando a educação: diversidade, descolonização e redes, de Muniz Sodré, e Idade mídia, de Alexandre Sayad. O tema, presente entre os trabalhos apresentados no IV Encontro Brasileiro de Educomunicação, em 2012, também está em um manual que foi recentemente disponibilizado pela Unesco. São livros atuais, que não podem faltar na bibliografia de disciplinas voltadas à reflexão epistemológica e ao planejamento da ação prática no campo da Educomunicação.

Palavras-chave: Mídia-educação; Educomunicação; educação; mídia; escola.
Abstract: This paper analyses three works that discuss - each one under a different perspective - the Media Education: Educomunicação: imagens do professor na mídia, organized by Adilson Citelli; Reinventando a educação: diversidade, descolonização e redes, by Muniz Sodré, and Idade Mídia, by Alexandre Sayad. The subject, present among the works presented in the IV Brazilian Educommunication Encounter, in 2012, is also included in a manual recently created by UNESCO. They are contemporary works, which cannot be missing in the bibliography of courses that make epistemological reflections and that discuss the planning of practical action in educommunication.

Keywords: Media Education; educommunication; media; school.

O movimento mundial em torno da Media Education (formação para uma convivência adequada em relação aos sistemas e meios de comunicação) sempre teve o propósito de levar o conhecimento sobre a mídia ao mundo da educação formal. A Unesco acaba de disponibilizar um manual denominado Media and Information Literacy Curriculum for Teachers ${ }^{1}$, sistematizando experiências de formação de audiências ativas e socializando roteiros a serem trabalhados em sala de aula, para orientar os alunos sobre como interagir com a informação disponibilizada nas redes e como fazer uso da produção midiática.

O tema esteve presente no IV Encontro Brasileiro de Educomunicação, celebrado em São Paulo, entre 25 e 27 de outubro de 2012, não apenas entre

1. Informações no site: <escolarhttp://www. unesco.org/new/en/ communication-and-information/resources/ publications-and-communication-materials/ publications/full-list/ media-and-information-literacy-curriculum-for-teachers/>. 
comunicação \& educação • Ano XV|l| • número 1 • jan/jun 2013

os 80 papers apresentados ao longo de todo o evento, mas também nos lançamentos ocorridos no último dia do evento.

Três lançamentos privilegiaram o tema, destacando - cada um sob uma perspectiva distinta - aspetos complementares da questão: Educomunicação: imagens do professor na mídia, coordenado por Adilson Citelli, que se volta para o olhar da mídia sobre um dos polos do processo educativo, o educador; Reinventando a educação: diversidade, descolonização e redes, de Muniz Sodré, que se propõe analisar os desafios colocados à educação pelos vários tipos de saberes, com destaque para o papel das tecnologias midiáticas e, finalmente, Idade mídia, de Alexandre Sayad, que narra uma experiência de reinvenção da mídia no contexto do ensino escolar formal.

\section{A MÍDIA, ENSINANDO SOBRE A EDUCAÇÃO}

O livro Educomunicação: imagens do professor na mídia reúne artigos que discutem a maneira como a imagem do professor é construída pela mídia; no caso, ao traduzir em representações estereotipadas o papel social do docente, cria referências que levam a uma padronização dos

Adilson Citelli (org.)

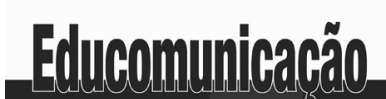

Imagens do professor na mídia aspectos físicos, emocionais, afetivos que caracterizam a conduta da categoria. Ao assim proceder, os meios de comunicação cumprem uma das funções a eles socialmente atribuída: a de nomear e categorizar, dando valor ao que descreve.

Segundo o coordenador da obra, Adilson Odair Citelli, professor titular da Escola de Comunicações e Artes da USP, as imagens e a representação dos professores presentes na mídia apresentam-se, efetivamente, como figura genérica, ganhando contornos discursivos modelares, cuja difusão pública registra uma vasta genealogia: indo da caricatura, passando pela constatação do desprestígio, da pura acusação de incompetência e inapetência profissional, até chegar às versões apocalípticas do fim de uma espécie que poderíamos chamar de homus docentis (p. 14-15).

É o que uma análise empírica do comportamento dos diferentes veículos de comunicação alcançou identificar. Para tanto, os autores visitaram a produção veiculada nos diferentes espaços midiáticos, representados pelo rádio ("A imagem do professor no rádio: aproximações, representações e miragens reconstituídas", de Ana Luisa Zaniboni Gomes); pela revista ("Discurso da qualidade na educação e invisibilidade do professor", de Helena Corazza); pelo jornal impresso ("Aula do crime: o discurso jornalístico e a imagem do professor", de Michel Carvalho da Silva); pela televisão ("Nas telas da TV: a representação do professor na "Turma 1901", de Elisangela Rodrigues da Costa); pelo cinema ("Pro dia nascer feliz: imagens da educação brasileira”, de Maria do Carmo Souza de Almeida); 
Reinventando a educação para reinventar a mídia - Ismar de Oliveira Soares

pela propaganda comercial ("O professor na propaganda comercial: roteiros e marcas", de Eliana Nagamini); pela propaganda institucional ("Ambiente escolar e a publicidade governamental", de Rogério Pelizzari de Andrade) e pela web ("Estigma ou emancipação: da imagem do professor na web à formação para a docência”, de Sandra Pereira Falcão).

\section{A EDUCAÇÃO REPENSANDO-SE FRENTE AO MUNDO DA MÍDIA}

O livro de Muniz Sodré, professor emérito da Universidade Federal do Rio de Janeiro, realiza uma análise sócio-histórica, partindo do lugar social onde nos situamos - o Hemisfério Sul -, colonizado em passado recente e vivendo, no momento, um forte processo de neodescolonização diante de um enfraquecido neoeurocentrismo. Muniz propõe que a educação se repense, superando os paradigmas que a constituíram como um serviço a um projeto de sociedade absolutamente em crise.

Prefaciando o livro, Leonardo Boff informa que a obra de Muniz, ao analisar as várias correntes da pedagogia e da educação, desde a paideia grega até o mercado mundial da educação, de faceta utilitarista, identifica no

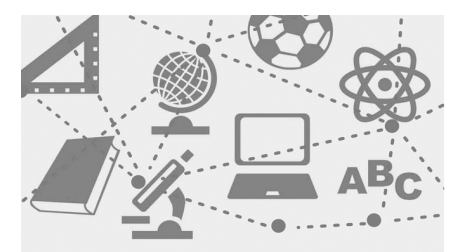

Muniz Sodré

REINVENTANDO A EDUCAÇÃO

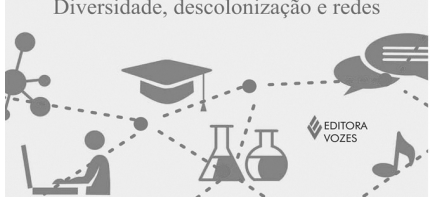
capitalismo-informacional-cognitivista o fundamento para o discurso responsável pelo aparato educacional contemporâneo, cuja base é a acumulação do capital. Esta é a razão pela qual a nova meta civilizatória para a educação mundial - e para a brasileira, igualmente - visa à formação de quadros que prestem "serviços simbólico-analíticos", quadros dotados de alta capacidade de inventar, identificar problemas e de resolvê-los. É nesse sentido, por exemplo, que Boff entende que o livro desmascara os mecanismos de poder econômico e político que se escondem atrás de expressões que estão na boca de todos, como "sociedade do conhecimento ou da informação".

A perspectiva defendida por Muniz, em busca da mudança, é o resgate das utopias representadas pelos nomes de intelectuais que, ao longo de nossa recente história, pensaram uma educação adequada às nossas virtualidades, e não exatamente aos modelos que nos são impostos do exterior, especialmente da Europa, como é o caso de Joaquim Nabuco, Anísio Teixeira e, particularmente, de Paulo Freire. Lembra igualmente Darcy Ribeiro, que falava com entusiasmo da "reinvenção do Brasil" a partir da riqueza da mestiçagem entre todos os representantes dos sessenta povos que vieram ao nosso país.

A proposta de Muniz é a de que "reinventemos a educação" para que a reinvenção do Brasil seja obra coletiva. 
comunicação \& educação • Ano XVIII • número 1 • jan/jun 2013

"A educação reinventada" - conclui Boff - "nos deve ajudar na descolonização e na superação do pensamento único, aprendendo com as diversidades culturais e tirando proveito das redes sociais. Deste esforço poderão nascer entre nós os primeiros brotos de outro paradigma de civilização que terá como centralidade a vida, a Humanidade e a Terra que alguns também chamam de civilização biocentrada”. Entendemos que a Educomunicação está sintonizada com esta perspectiva.

\section{REINVENTANDO A MÍDIA}

Ao longo das últimas décadas, multiplicaram-se, pelo Brasil, experiências de construção de projetos em que professores e alunos tomaram a mídia como objeto de análise e de experimentação. Trata-se de propostas de reflexão/ação identificadas como práticas de mídia-educação.

Presentes em organizações do Terceiro Setor, as propostas de análise do comportamento da mídia passam, paulatinamente, do embate ideológico (a condenação do que se entende como programação de baixa qualidade) para o esforço de apropriação de suas linguagens no espaço escolar (a produção de mídia pelos próprios alunos). É o que defende a Educomunicação, quando propõe que, para bem analisar a mídia (a produção de terceiros), há que se exercitar a produção, sob paradigmas que privilegiem o fazer comunicativo como uma

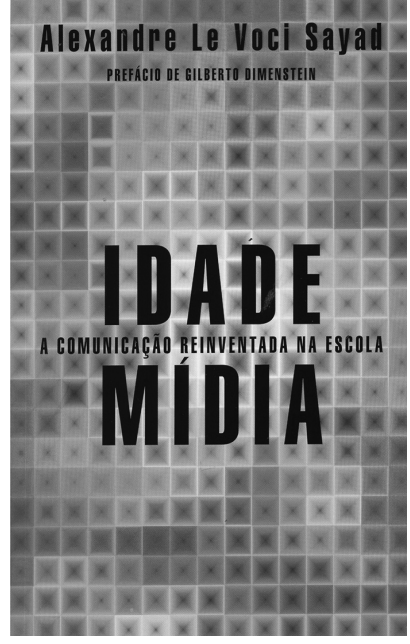
ação coletiva e solidária, seguindo-se a avaliação sobre a qualidade do processo e do produto, de forma a criar parâmetros de avaliação aplicáveis a outras circunstâncias e a outros produtos.

Fora do ambiente mais aberto e permeável das ONGs, é no espaço mais complexo da educação formal, numa escola destinada à classe média alta - o Colégio Bandeirantes, na capital paulista -, que vamos encontrar a experiência relatada por Alexandre Sayad, em seu livro Idade mídia.

A brecha tem sido a prática de pedagogia de projetos, adotada pela escola, reconhecendo a Educomunicação como um instrumento válido de ação junto a uma juventude aberta à inovação, para além do que dela se espera no competitivo mundo das provas vestibulares.

No livro, o leitor vai encontrar o debate sobre a natureza da prática de educação "para" e "com" a mídia. Em algum momento, o autor é explícito: diz aquilo que o projeto não é (nem um curso profissionalizante de comunicação; nem mesmo um curso sobre leitura crítica da mídia); em outro momento, afirma o que a experiência pretende ser (a "reinvenção" da prática educativa). Explica Sayad: 
Reinventando a educação para reinventar a mídia - Ismar de Oliveira Soares

Reinvenção é a palavra de ordem do Idade Mídia; esse talvez seja o principal elemento que explique a continuidade do projeto - importante para mantê-lo em compasso com o mundo e os jovens estudantes. O conceito preserva uma ambição ativa: a de revirar permanentemente os paradigmas tradicionais da educação. Em outras palavras, o desejo permanente de deixar a educação pronta para lidar com todos os desafios impostos para uma sociedade cada vez mais veloz.

O projeto mostra, por outro lado, a figura do novo profissional da interface, atuando no novo mercado que emerge dos caminhos cruzados entre a educação e a comunicação. Temos aqui o perfil do profissional que algumas universidades (entre as quais a USP) esperam formar. Uma notícia nada mal, em tempos de crises de identidade profissional e de empregabilidade!

Estamos falando, pois, do educomunicador, identificado como um trabalhador muito procurado, ainda que nem sempre facilmente identificável. Aqui está ele: um operário criativo, reconhecido pelas surpreendentes ações geradas a partir da riqueza contida nas diferentes formas de expressão comunicativa, e que consegue promover, junto às novas gerações, o crescimento comunitário.

Em outras palavras, o livro vem comprovar que a Educomunicação, efetiva quando aplicada aos espaços próprios da educação não formal, pode transformar-se, de igual maneira, numa aliada no espaço da educação formal, através de uma bem arquitetada pedagogia de projetos.

Por outro lado, a leitura dos capítulos do livro permite ao observador perceber que o tratamento educomunicativo, presente na relação entre mídia e educação, favorece especialmente o desenvolvimento qualitativo dos alunos em três grandes esferas: na esfera da política (a socialização do poder de se comunicar); na esfera da ética (a vivência e disseminação de princípios como o da sustentabilidade e o da responsabilidade social, em relação a toda a comunidade humana) e na esfera da estética (a valorização das diferentes formas de apreciação da arte e do belo e - mais no âmago da questão - da própria produção da arte e do belo). Inteligência e sensibilidade se unem a uma determinada forma de conceber e, especialmente, de expressar o mundo.

Se, no passado, o ponto de vista hegemônico de se olhar o binômio mídia e educação era predominantemente instrumentalista, experiências como as narradas por Sayad permitem descobrir uma perspectiva dialética no processo mediado pelo educomunicador, levando o aluno a descobrir que, mais importante que saber o que pode a mídia fazer por ele ou contra ele, é saber o que ele e sua comunidade podem fazer, juntos, com os recursos disponibilizadas pela era da informação e da comunicação.

À pergunta que muitos se fazem: Afinal, existe o educomunicador? O livro de Sayad dá a resposta: sim! Desde que seja um profissional inconformado com a naturalização dos modelos verticalistas de comunicação e de educação, e um ativista da criatividade na busca de novas razões culturais, políticas e éticas, para uma ação que beneficie os excluídos dos processos de produção simbólica e midiática. 
comunicação \& educação • Ano XV|ll • número 1 • jan/jun 2013

\section{EPISTEMOLOGIA DA EDUCOMUNICAÇÃO}

Os livros de Adilson Odair Citelli, Muniz Sodré e Alexandre Sayad não podem faltar na bibliografia de disciplinas voltadas à reflexão epistemológica e ao planejamento da ação prática no campo da Educomunicação. É o que propomos que passe a vigorar, a partir deste momento, nas disciplinas de licenciatura em Educomunicação da própria ECA/USP.

Sugerimos que os livros sejam apropriados na sequência apresentada por esta resenha, permitindo que novas referências sejam incorporadas ao estudo dos fundamentos da educomunicação, bem como aos exercícios em torno de sua ética e de sua prática em suas diferentes áreas e espaços de atuação.

\section{REFERÊNCIAS BIBLIOGRÁFICAS}

CITELLI, Adilson (org.). Educomunicação: imagens do professor na mídia. São Paulo: Paulinas, 2012.

SAYAD, Alexandre. Idade mídia. São Paulo: Editora Alef/Editora Jatobá, 2011.

SODRÉ, Muniz. Reinventando a educação: diversidade, descolonização e redes. Petrópolis: Vozes, 2012. 